\title{
Stability of a Bifunctional Cu-Based Core@Zeolite Shell Catalyst for Dimethyl Ether Synthesis Under Redox Conditions Studied by Environmental Transmission Electron Microscopy and In Situ X-Ray Ptychography
}

Sina Baier, ${ }^{1}$ Christian D. Damsgaard, ${ }^{2,3}$ Michael Klumpp, ${ }^{4}$ Juliane Reinhardt, ${ }^{5}$ Thomas Sheppard, ${ }^{1,6}$ Zoltan Balogh, ${ }^{2}$ Takeshi Kasama, ${ }^{2}$ Federico Benzi, ${ }^{1}$ Jakob B. Wagner, ${ }^{2}$ Wilhelm Schwieger, ${ }^{4}$ Christian G. Schroer, ${ }^{5,7}$ and Jan-Dierk Grunwaldt ${ }^{1,6, *}$

\footnotetext{
${ }^{1}$ Institute for Chemical Technology and Polymer Chemistry, Karlsruhe Institute of Technology, 76131 Karlsruhe, Germany

${ }^{2}$ Center for Electron Nanoscopy, Technical University of Denmark, 2800 Kgs. Lyngby, Denmark

${ }^{3}$ Department of Physics, Center for Individual Nanoparticle Functionality, Technical University of Denmark, 2800 Kgs. Lyngby, Denmark

${ }^{4}$ Institute of Chemical Reaction Engineering, Friedrich-Alexander University Erlangen-Nürnberg (FAU), 91058 Erlangen, Germany ${ }^{5}$ Deutsches Elektronen-Synchrotron DESY, Notkestr. 85, 22607 Hamburg, Germany

${ }^{6}$ Institute of Catalysis Research and Technology, Karlsruhe Institute of Technology, 76344 Eggenstein-Leopoldshafen, Germany

${ }^{7}$ Department Physik, Universität Hamburg, Luruper Chaussee 149, 22761 Hamburg, Germany
}

\begin{abstract}
When using bifunctional core@shell catalysts, the stability of both the shell and core-shell interface is crucial for catalytic applications. In the present study, we elucidate the stability of a $\mathrm{CuO} / \mathrm{ZnO} / \mathrm{Al}_{2} \mathrm{O}_{3} @ \mathrm{ZSM}-5$ core@shell material, used for one-stage synthesis of dimethyl ether from synthesis gas. The catalyst stability was studied in a hierarchical manner by complementary environmental transmission electron microscopy (ETEM), scanning electron microscopy (SEM) and in situ hard X-ray ptychography with a specially designed in situ cell. Both reductive activation and reoxidation were applied. The core-shell interface was found to be stable during reducing and oxidizing treatment at $250^{\circ} \mathrm{C}$ as observed by ETEM and in situ X-ray ptychography, although strong changes occurred in the core on a $10 \mathrm{~nm}$ scale due to the reduction of copper oxide to metallic copper particles. At $350^{\circ} \mathrm{C}$, in situ X-ray ptychography indicated the occurrence of structural changes also on the $\mu \mathrm{m}$ scale, i.e. the core material and parts of the shell undergo restructuring. Nevertheless, the crucial core-shell interface required for full bifunctionality appeared to remain stable. This study demonstrates the potential of these correlative in situ microscopy techniques for hierarchically designed catalysts.
\end{abstract}

Key words: core-shell catalyst, dimethyl ether, correlative imaging, ETEM, X-ray microscopy

\section{INTRODUCTION}

In recent years, core@shell materials with hierarchical structures spanning different length scales have attracted a lot of attention in heterogeneous catalysis, as their unique structure has been shown to result in enhanced catalytic behavior (Zhong \& Maye, 2001; Sankar et al., 2012; Zaera, 2013; Schwieger et al., 2016). These materials require characterization on different length scales, where microscopic studies are one of the key techniques available (Weckhuysen, 2009; Basile et al., 2010; Grunwaldt \& Schroer, 2010; Andrews \& Weckhuysen, 2013; Grunwaldt et al., 2013). In general, core@shell-type catalysts can be divided into three groups based on the specific function of the core and the shell:

(i) Bimetallic core@shell nanoparticles (Zhong \& Maye, 2001; Huang et al., 2010; Sankar et al., 2012; Zaera, 2013)

Received July 1, 2016; accepted February 11, 2017

${ }^{*}$ Corresponding author. grunwaldt@kit.edu in which the catalytic activity of the surface is improved by the core@shell design (length scale: 2-50 nm).

(ii) Catalyst core@porous inert shell (Lee et al., 2011; $\mathrm{Xu}$ et al., 2013) in which the catalyst lifetime can be improved by encapsulation of the catalytically active core in a porous, protective shell or inside pores (usually in the length scale: 5-200 nm). This can prevent catalyst deactivation through sintering or coking for example.

(iii) Catalyst core@porous catalyst shell structures for consecutive, e.g. two-step reactions (Yang et al., 2007, 2010, 2012, 2013; Bao et al., 2011; Lee et al., 2011; Li et al., 2012, 2015a; Nie et al., 2012; Pinkaew et al., 2013; Wang et al., 2013, 2014; Ding et al., 2015; Garcia-Trenco \& Martinez, 2015; Phienluphon et al., 2015), in which the hierarchical combination of two catalytically active materials in a core@shell arrangement enables two reaction steps in one single process stage [length scale: $500 \mathrm{~nm}$ to millimeters, called product design ( $\mathrm{Ng}$ et al. 2007)]. 
Although the latter combination can also be realized using hybrid catalysts or physical mixtures (Ge et al., 1998; Prasad et al., 2008; Abu-Dahrieh et al., 2012; Ahmad et al., 2014; Allahyari et al., 2014; Gentzen et al., 2016), the core@ shell design additionally allows exploitation of synergistic effects. Because of the hierarchical ordering of active sites in the core and shell, products formed at the core have to diffuse through the porous shell and can thereby be converted into the final reaction product. Hence, the product formed at the core is constantly removed by the subsequent reaction shifting the equilibrium to the product side. This has been demonstrated for the synthesis of hydrocarbons from synthesis gas (syngas), via the combination of Fischer-Tropsch synthesis and subsequent cracking/isomerization in a core@shell catalyst (core: Fischer-Tropsch catalyst, shell: solid acid catalyst) (Yang et al., 2007, 2013; Bao et al., 2008, 2011; Sun et al., 2012) and likewise, for the one-stage synthesis of dimethyl ether (DME) from synthesis gas (Yang et al., 2010, 2012; GarciaTrenco et al., 2012; Li et al., 2012; Nie et al., 2012; Pinkaew et al., 2013; Wang et al., 2013, 2014; Ding et al., 2015; Phienluphon et al., 2015). The latter system presently receives a lot of attention, as DME is a high-value platform chemical that can be further processed into a wide range of products. DME is regarded as a promising clean fuel because of its low soot, $\mathrm{CO}$ and $\mathrm{NO}_{\mathrm{x}}$ emissions as well as its good storage possibilities (Azizi et al., 2014), especially when sourced from "green" synthesis gas derived from biomass gasification (Dahmen et al., 2012). In general, the two reaction steps for DME synthesis are methanol formation over e.g. a $\mathrm{Cu} / \mathrm{ZnO}$-based catalyst and its subsequent dehydration over a solid acid catalyst such as a zeolite [e.g., MFI-type zeolite H-ZSM-5 (Li et al., 2012; Nie et al., 2012; Yang et al., 2012; Ding et al., 2015; Garcia-Trenco \& Martinez, 2015) and silicoaluminophosphates (Pinkaew et al., 2013; Phienluphon et al., 2015)] or alumina (Hayer et al., 2011; Wang et al., 2013, 2014).

As shown in Figure 1, in such a bifunctional core@shell catalyst, the two functionalities are arranged in such a way that the reactants (synthesis gas) have to diffuse to the core where methanol is formed. Once formed, the concentration gradient forces methanol to diffuse through the acidic shell, where it is subsequently converted to DME. At the same time, the nearby consumption of methanol promotes the synthesis gas conversion (Ge et al., 1998; Prasad et al., 2008; Abu-Dahrieh et al., 2012; Allahyari et al., 2014; Gentzen et al., 2016).

Because of the strong dependence of activity and selectivity on the catalyst structure, it is important that the core-shell interface remains stable, even under reaction conditions or strongly reducing conditions required for catalyst activation. To assess the stability of the catalyst, a hierarchical in situ imaging approach is required on all length scales to uncover the specific functional catalytic properties: from the atomic scale $(0.1-5 \mathrm{~nm})$, to the interfaces on an intermediate length scale $(20-500 \mathrm{~nm})$, and the full structure of particles on the micrometer $(\mu \mathrm{m})$ scale (Weckhuysen, 2009; Basile et al., 2010; Grunwaldt \& Schroer, 2010; Andrews \& Weckhuysen, 2013; Grunwaldt et al., 2013). Several techniques have been developed during the past

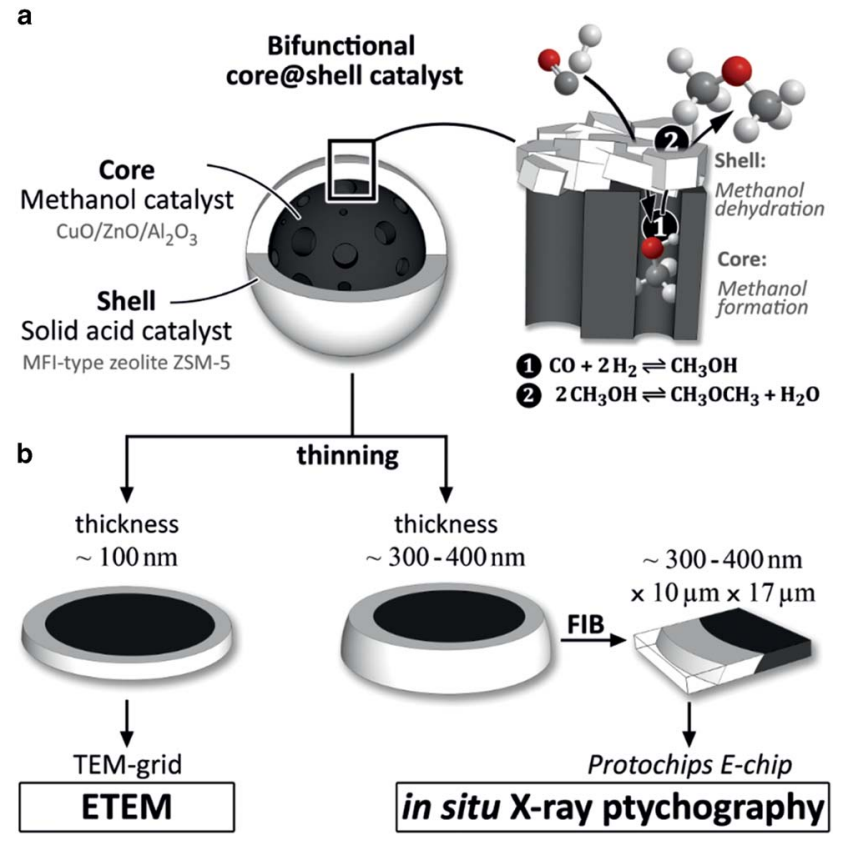

Figure 1. Schematic representation of (a) the bifunctional core@ shell catalyst and the two main chemical reactions in direct dimethyl ether synthesis from synthesis gas and (b) the principle sample preparation for environmental transmission electron microscopy (ETEM) and in situ X-ray ptychography. FIB, focused ion beam.

years. On the one hand X-ray microscopy with X-ray absorption, diffraction (XRD), and fluorescence contrast has been found to give information on the $\mu \mathrm{m}$ and sub- $\mu \mathrm{m}$ scale (Meirer et al., 2011), even under in situ (Price et al., 2015b) and quasi in situ conditions (Markötter et al., 2011; Hofmann et al., 2015). On the other hand, electron microscopy including electron tomography has been developed for gaining insight on the atomic level (Hansen et al., 2002; Goris et al., 2012). Using differentially pumped microscopes (Hansen \& Wagner, 2012) or closed cells (Creemer et al., 2010), in situ studies are possible but are still constrained with respect to sample dimensions and gas pressure. Although the spatial resolution with hard X-rays is limited, they offer a higher penetration depth and allow imaging under more realistic reaction conditions (de Smit et al., 2008; de Groot et al., 2010; Falcone et al., 2011; Cats et al., 2013) and thus the complementary use of these electron and X-ray microscopy techniques is beneficial (Thomas \& HernandezGarrido, 2009; Li et al., 2015b; Stach et al., 2015). In particular, hard X-ray ptychography (Schroer et al., 2010; Høydalsvik et al., 2014) as a high-resolution X-ray microscopy technique has reached spatial resolutions below $10 \mathrm{~nm}$ (Vila-Comamala et al., 2011; Schropp et al., 2012) and is thus attractive for in situ studies (Baier et al., 2016a). In addition, the application of resonant X-ray ptychography offers chemical contrast (Beckers et al., 2011; Hoppe et al., 2013), and if the coherent small-angle X-ray scattering (SAXS) contribution is analyzed, further information on nanostructured materials can be obtained, for example from in situ anomalous SAXS (Andreasen et al., 2006). 
Here we examine the potential to investigate the structure and stability of a core@shell catalyst for direct synthesis of DME using complementary in situ X-ray ptychography and environmental transmission electron microscopy (ETEM). The bifunctional catalyst consists of a $\mathrm{CuO} / \mathrm{ZnO} /$ $\mathrm{Al}_{2} \mathrm{O}_{3}$ core, encapsulated within a zeolite ZSM-5 shell. As the $\mathrm{CuO} / \mathrm{ZnO}$ system usually undergoes structural changes upon reduction and under reaction conditions (Grunwaldt et al., 2000; Andreasen et al., 2006; Holse et al., 2015; Studt et al., 2015; Kuld et al., 2016), it may influence the stability of the core-shell interface, especially since volume changes of $42 \%$ (reduction to metallic $\mathrm{Cu}$ ) and $72 \%$ (reoxidation to $\mathrm{CuO}$ ) are expected (Holse et al., 2015). The complementary nature of the two microscopic methods was exploited on model thin slices to probe the catalyst stability on the atomic scale using in situ electron microscopy (model conditions), and at ambient pressure on a thicker sample and larger sample area using in situ X-ray ptychography (Fig. 1).

\section{Materials and Methods}

\section{Catalyst Preparation}

A microsized core@shell catalyst was prepared according to the procedure described previously (Ding et al., 2015). In brief, a commercial $\mathrm{CuO} / \mathrm{ZnO} / \mathrm{Al}_{2} \mathrm{O}_{3}$ methanol catalyst was ground and sieved to a size of $80-100 \mu \mathrm{m}$. The shell was synthesized via the two-step hydrothermal synthesis approach of in situ silicalite-1 seeding, followed by the secondary growth of a ZSM-5 zeolite shell. After calcination, $\mathrm{CuO} / \mathrm{ZnO} / \mathrm{Al}_{2} \mathrm{O}_{3} @ \mathrm{H}-$ ZSM-5 particles with a mean shell thickness of $\sim 5 \mu \mathrm{m}$ were obtained and further processed. The catalyst was characterized by scanning electron microscopy (SEM) and powder XRD (see Supplementary Figs. 1 and 2).

\section{Supplementary Figures 1 and 2}

Supplementary Figures 1 and 2 can be found online. Please visit journals.cambridge.org/jid_MAM.

\section{Sample Preparation for Electron Microscopy, ETEM and In Situ X-Ray Ptychography}

The calcined core@shell catalyst particles were embedded between two pieces of silicon substrate using a M-bond 610 (Agar Scientific Ltd, Stansted, UK) resin. After drying at $110^{\circ} \mathrm{C}$ for $24 \mathrm{~h}$, the sample was polished from two sides to obtain a thin cross-section. This section was fixed between two molybdenum transmission electron microscopy (TEM) grids with a $1 \mathrm{~mm}$ aperture and further thinned down using argon ion milling. By this approach, a 100-nm-thick sample with a wedge shape was obtained, which was directly used for ETEM imaging (Fig. 1b).

For in situ X-ray ptychography, a $300-400 \mathrm{~nm}$ thick sample (prepared as described above for the ETEM study, Fig. 1b) was transferred into a focused ion beam (FIB) microscope to be further processed. FIB micromanipulation was used to cut a piece of $10 \times 17 \mu \mathrm{m}^{2}$, containing the core-shell interface. This piece was then transferred to a Protochips E-Chip $^{\mathrm{TM}}$ (Protochips, Inc., Morrisville, NC, USA) (Allard et al., 2009) and fixed on the chip by platinum deposition. For FIB micromanipulation, a FEI Helios EBS3 dual beam microscope located at the Center for electron nanoscopy (Cen) of the Technical University of Denmark (DTU) was used.

\section{Electron Microscopy}

SEM images were collected on: (a) polished cross-sections of embedded catalyst grains (M-bond 610) and (b) samples prepared for in situ X-ray ptychography (described previously). Images were obtained using backscattered electron (BSE) contrast with the FEI Helios EBS3 dual beam microscope (FEI, Hillsboro, OR, USA) located at DTU-Cen operating at $5 \mathrm{kV}$. Energy dispersive X-ray spectroscopy (EDX) mapping was performed at $5 \mathrm{kV}$ using an EDAX SD Apollo 10 Pegasus System (AMETEK, Mahawah, NJ, USA). After the in situ X-ray ptychography, BSE-SEM images were recorded using a Zeiss Auriga 60 dual beam FIB system (Carl Zeiss AG, Oberkochen, Germany) at the Karlsruhe Nano Micro Facility (KNMF), located at the Institute for Nanotechnology at Karlsruhe Institute of Technology (KIT). EDX mapping was performed at $5 \mathrm{kV}$ (EDAX Octane Super System: AMETEK, Mahawah, NJ, USA).

Bright field TEM was performed for comparison between phase contrast images obtained by in situ X-ray ptychography, using a FEI Tecnai T20 G ${ }^{2}$ (FEI, Hillsboro, OR, USA) operating at $200 \mathrm{kV}$. For in situ studies under varying reducing/ oxidizing conditions, ETEM was performed at $300 \mathrm{kV}$ using a FEI Titan E-Cell 80-300 ST TEM (FEI, Hillsboro, OR, USA) equipped with an aberration corrector for the objective lens. Scanning transmission electron microscopy (STEM) images were acquired by a Fischione model 3000 (E.A. Fischione Instruments, Export, PA, USA) high-angle annular dark field (HAADF) STEM detector and electron energy loss spectroscopy (EELS) was performed using a Gatan Tridiem Imaging Filter (Gatan, Inc., Pleasanton, CA, USA). For reduction, $\mathrm{H}_{2}$ at a pressure of $1.1 \mathrm{mbar}$ was applied for $30 \mathrm{~min}$ while the sample was heated up to $250^{\circ} \mathrm{C}$ at a heating rate of $10^{\circ} \mathrm{C} / \mathrm{min}$. The sample was kept under reducing atmosphere for $90 \mathrm{~min}$ until the EELS signal appeared stable before images were considered to represent the reduced state. For reoxidation, the sample was kept at $250^{\circ} \mathrm{C}$, evacuated and $\mathrm{O}_{2}$ was inserted until a pressure of $3.2 \mathrm{mbar}$ was reached. STEM images were acquired after $90 \mathrm{~min}$ of gas exposure. TEM measurements were performed at DTU-Cen.

\section{In Situ X-Ray Ptychography}

In situ X-ray ptychography was performed starting with the core-shell interface region of the calcined catalyst, mounted on a Protochips E-Chip ${ }^{\mathrm{TM}}$ (Allard et al., 2009). Here, a dedicated in situ cell (Baier et al., 2016a) based on heating by Protochips E-Chip ${ }^{\mathrm{TM}}$ with $\mathrm{Si}_{3} \mathrm{~N}_{4}$ windows of $\sim 50 \mathrm{~nm}$ in thickness was used. The cell enables heating under a controlled gas atmosphere. A flow of $3 \mathrm{~mL} / \mathrm{min}$ of $4 \% \mathrm{H}_{2} / \mathrm{He}$ was 
used for reduction, whereas $3 \mathrm{~mL} / \mathrm{min}$ of $20 \% \mathrm{O}_{2} / \mathrm{N}_{2}$ was used for reoxidation. The samples were heated using the resistive heating capability of the E-chip ${ }^{\mathrm{TM}}$. For the different temperature steps, the temperature was determined by Infrared (IR) thermography with an ImageIR ${ }^{\circledast} 8300$ camera from InfraTec (InfraTec GmbH, Dresden, Germany) equipped with a macro objective $\mathrm{M}=1.0 \times$ with a field of view of $9.6 \times 7.7 \mathrm{~mm}$ and a pixel size of $15 \mu \mathrm{m}$ [as described in Baier et al. (2016b)] and heating rates of $\sim 10^{\circ} \mathrm{C} / \mathrm{min}$ were applied. Before changing the gas atmosphere, the temperature was temporarily decreased by $100^{\circ} \mathrm{C}$ to avoid sudden temperature changes due to different thermal conductivity of the gases. However, short temperature spikes of about $150^{\circ} \mathrm{C}$ could not be avoided completely. The sample was kept at each condition for $3 \mathrm{~h}$ such that it was exposed to the $\mathrm{X}$-ray beam for $15 \mathrm{~h}$ in total. No effects directly related to the exposure to the X-ray beam could be observed.

In situ X-ray ptychography was performed at the P06 Nanoprobe endstation of the high brilliance synchrotron light source PETRA III at DESY, Hamburg, using a photon energy of $9.032 \mathrm{keV}$. The beam was focused using a coherently illuminated zone-doubled Fresnel zone plate (Vila-Comamala et al., 2011) made of iridium with a diameter of $150 \mu \mathrm{m}$ and an outer-most zone width of $25 \mathrm{~nm}$, corresponding to a focal length of about $27 \mathrm{~mm}$ at this energy. The samples were placed at a distance of about $60 \mu \mathrm{m}$ downstream from the focus, such that the illumination on the sample had a diameter of about $260 \mathrm{~nm}$. Ptychographic scans were recorded by scanning the sample over a field of view of $5 \times 5 \mu \mathrm{m}^{2}$ in a grid of $60 \times 60$ steps with a step size of $80 \mathrm{~nm}$. At each scanning position diffraction patterns of $0.5 \mathrm{~s}$ exposure time were recorded with an EIGER X $4 \mathrm{M}$ detector (DECTRIS Ltd, Baden-Daettwil, Switzerland) with $75 \mu \mathrm{m}$ pixel size placed $2.1 \mathrm{~m}$ downstream from the specimen. Including motor movements, the total duration of one scan was about $45 \mathrm{~min}$.

The algorithm used for reconstruction was based on the (e)PIE algorithm presented by Maiden \& Rodenburg (2009). Cropping the diffraction patterns to $256 \times 256$ pixels led to a pixel size of $\sim 15 \mathrm{~nm}$ in the reconstructed images. To estimate the spatial resolution, a Fourier ring correlation (FRC) analysis (van Heel \& Schatz, 2005) was performed. As a common procedure, the ptychographic data set was split in two, with each set containing every second scan point. Afterwards, the ptychographic reconstruction was performed for each of these half data sets. Before correlating the phase reconstruction, a Kaiser-Bessel window function with a size equal to 1.5 was applied to the images, in order to reduce artifacts caused by erroneous high frequencies resulting from the edges of the limited field of view of the reconstructions. The FRC results in an upper limit for the spatial resolution of about $28 \mathrm{~nm}$ (see Supplementary Fig. 3).

\section{Supplementary Figure 3}

Supplementary Figure 3 can be found online. Please visit journals.cambridge.org/jid_MAM.

\section{Results And Discussion}

\section{Electron Microscopy}

The core@shell particles were first studied in the as-prepared state by ex situ SEM. A cross-section BSE-SEM image is shown in Figure 2. In Figure 2a, the general core-shell structure is clearly visible, revealing a shell with $\sim 5 \mu \mathrm{m}$ thickness, and a core diameter of around $70 \mu \mathrm{m}$. Apart from the evident core-shell structure, the shell varied in appearance or integrity, from a continuous well-connected structure shown in Figure 2c (dashed white box in Fig. 2a), to a more fractured appearance (solid white box in Fig. 2a) presented in Figure $2 b$. The latter areas, especially cracks continuing to the surface of the particle, are expected to be problematic in maintaining bifunctionality, because methanol can escape without dehydration to DME. The well-connected core-shell interface is therefore considered to be a desirable feature. Because of the application of BSE contrast, which is sensitive to changes in the mean atomic number ( $Z$ ) of a material (brighter corresponds to higher $Z$ ), the inhomogeneous nature of the core can be observed, revealing irregularly distributed high- $\mathrm{Z}$ material as well as large pores $(\sim 5 \mu \mathrm{m})$. Figure 3 shows STEM-HAADF images of a well intergrown part of the core-shell interface. The shell (Fig. 3b) seems to be in close contact to the core material with a complete coverage of needle-shaped core material intergrown with the zeolite shell.

To study the stability of the core-shell interface during activation under model gas conditions, $\sim 100 \mathrm{~nm}$ thick coreshell interface (Fig. 3) was studied during reduction $\left(1.1 \mathrm{mbar}^{\mathrm{H}} \mathrm{H}_{2}\right.$ ) and reoxidation $\left(3.2 \mathrm{mbar} \mathrm{O}_{2}\right.$ ) with ETEM. Both treatments were conducted at $250^{\circ} \mathrm{C}$. Figure 4 shows three STEM-HAADF images from the core-shell interface (top) and corresponding EELS on the core area (bottom). In the top row, the interface between the bright core on the right and the darker shell on the left of the images is visible. A darker area was visible in the center of the core area of the reduced sample (Fig. 4b), compared with the as-prepared and reoxidized sample (Figs. 4a, 4c, respectively), showing a size decrease of the bright core material. This observation is in agreement with the expected shrinkage of $\mathrm{CuO}$ particles on reduction to metallic Cu of about $42 \%$ (Holse et al., 2015). Upon reoxidation the particle size apparently increased again, revealing a brighter center of the image, although the $\mathrm{Cu}$-containing phases appear less defined. Notably, the coreshell interface itself remained unchanged during redox treatment. In addition to imaging during the redox treatment, EELS analysis was performed to qualitatively determine the oxidation state of copper, due to limitations in sample thickness. The decrease in the characteristic $\mathrm{Cu} \mathrm{L}_{2}, \mathrm{~L}_{3}$ edges for $\mathrm{CuO}$ from Figures $4 \mathrm{a}$ and $4 \mathrm{~b}$ indicates successful reduction of copper by treatment in $\mathrm{H}_{2}$. Reoxidation was indicated by an increase in the white line intensity (Fig. 4c).

Figure 5 shows the core-shell interface region during the same treatment at higher spatial resolution. Changes with respect to the image under previous conditions are highlighted by red arrows. In accordance with the behavior 

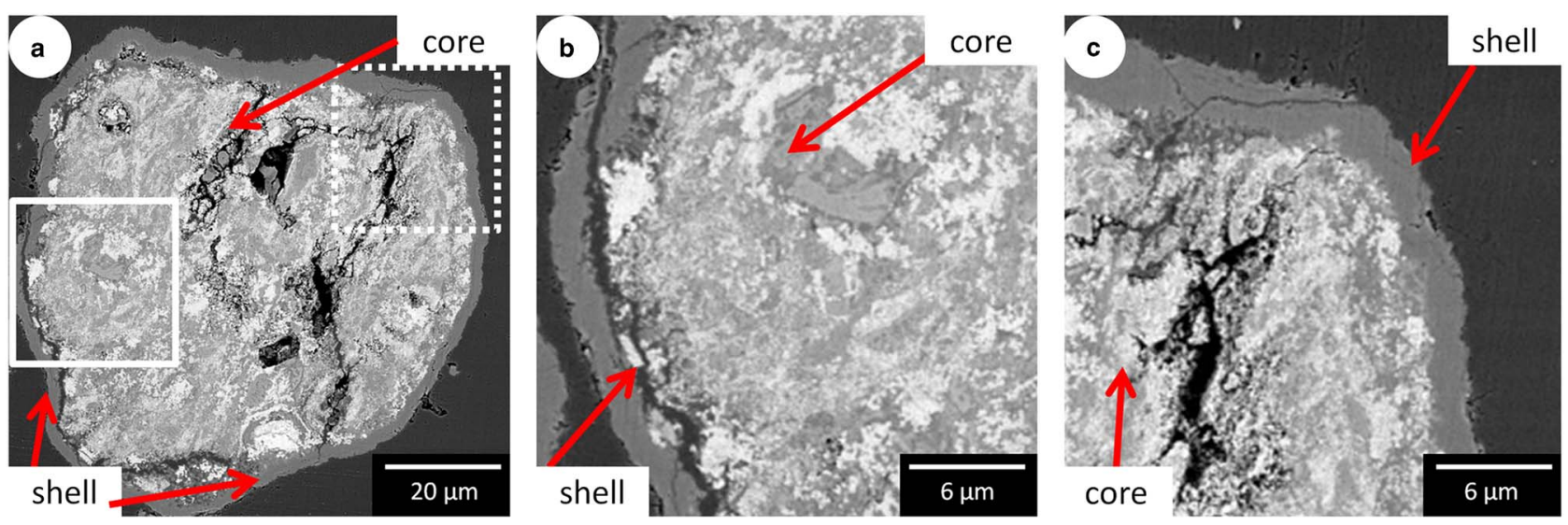

Figure 2. Scanning electron microscopy (SEM) images of a cross-section recorded at $5 \mathrm{kV}$ in backscattered electron contrast revealing the core-shell structure of the as-prepared catalyst material: (a) overview image; (b) zoom into the solid marked area revealing a nonconnected part of the shell and a crack filled with resin; (c) zoom into the dashed marked area revealing the stable connection of the core and the shell and voids inside the core.
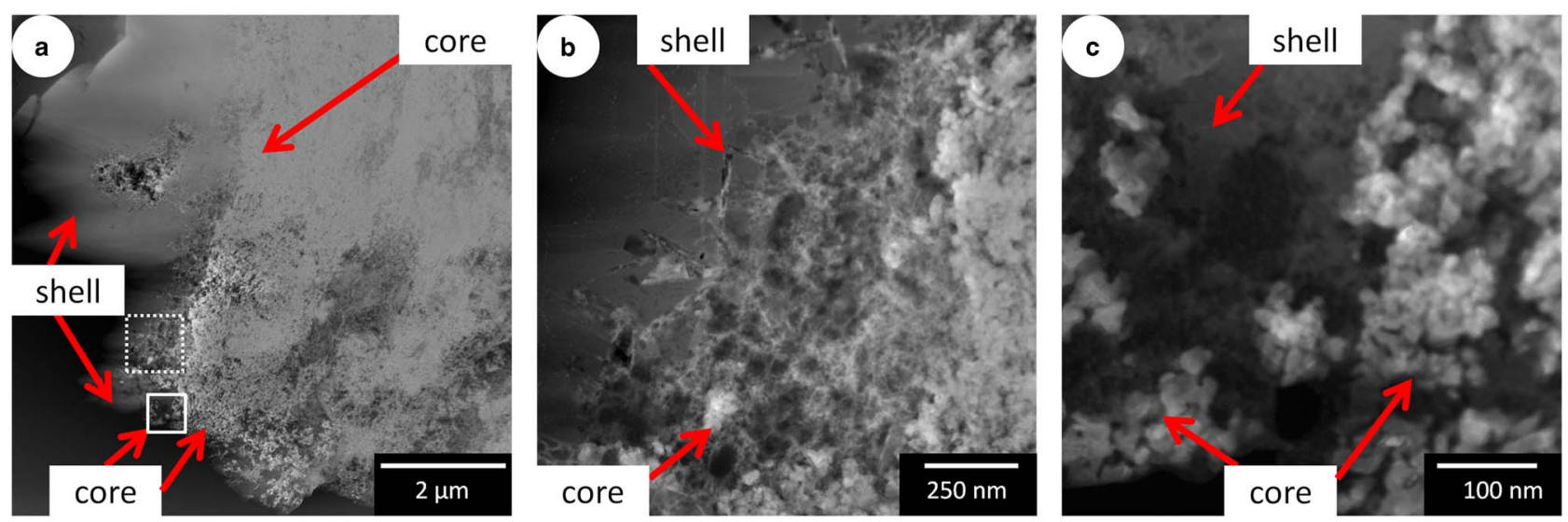

Figure 3. Scanning transmission electron microscopy-high-angle annular dark field images of the core-shell interface of a polished thin section of the catalyst particle, revealing the stable connection of the core and the shell: (a) micrometer length scale and nanometer scale; (b) zoom in on dashed marked area; (c) zoom in on the solid marked area.

observed in Figure 4, the Cu-containing core particles became more separated and defined, with longer interparticle distances on the nanometer $(\mathrm{nm})$ scale during reduction, possibly due to the volume decrease of the $\mathrm{Cu}$ particles formed by reduction of $\mathrm{CuO}$. After reoxidation, the area occupied by $\mathrm{Cu}$-containing material increased again, the interparticle pores decreased and the particles became less defined. This indicates restructuring by oxidation and associated volume increase of the oxidized $5-20 \mathrm{~nm}$ particles. Despite these apparent changes in the core structure, the core-shell interface on the $500 \mathrm{~nm}$ to $1 \mu \mathrm{m}$ scale remained stable and the shell area did not show any significant differences on this length scale. This might be explained by the thermal stability of the zeolite and the inertness to redox conditions. In addition, the porosity of the core material may allow changes in the core region on the $10 \mathrm{~nm}$ scale without affecting the shell on the $\mu \mathrm{m}$ scale. It should be noted that a real core@shell particle with a spherical shape may behave differently than the slice of the core-shell interface studied here, which resulted from the sample preparation procedure.
However, such studies using the whole three-dimensional (3D) particle of this size non-invasively are not currently feasible by in situ electron microscopy.

\section{In Situ X-Ray Ptychography}

To extend the hierarchical approach of catalyst characterization and to follow reductive activation, a core-shell interface was additionally studied during the corresponding redox treatments under ambient pressure using in situ X-ray ptychography. Thanks to the higher penetration depth of hard X-rays, a thicker sample $(\sim 300-400 \mathrm{~nm})$ could be investigated. Phase contrast images obtained during in situ X-ray ptychography at different temperatures, along with inverted contrast BSE-SEM images under vacuum conditions before and after in situ treatment are depicted in Figure 6. Changes with respect to the previous image are highlighted by black arrows, whereas blue arrows are used to mark the same positions in the sample. The sample was placed on a Protochips E-Chip ${ }^{\mathrm{TM}}$, which contains electron 

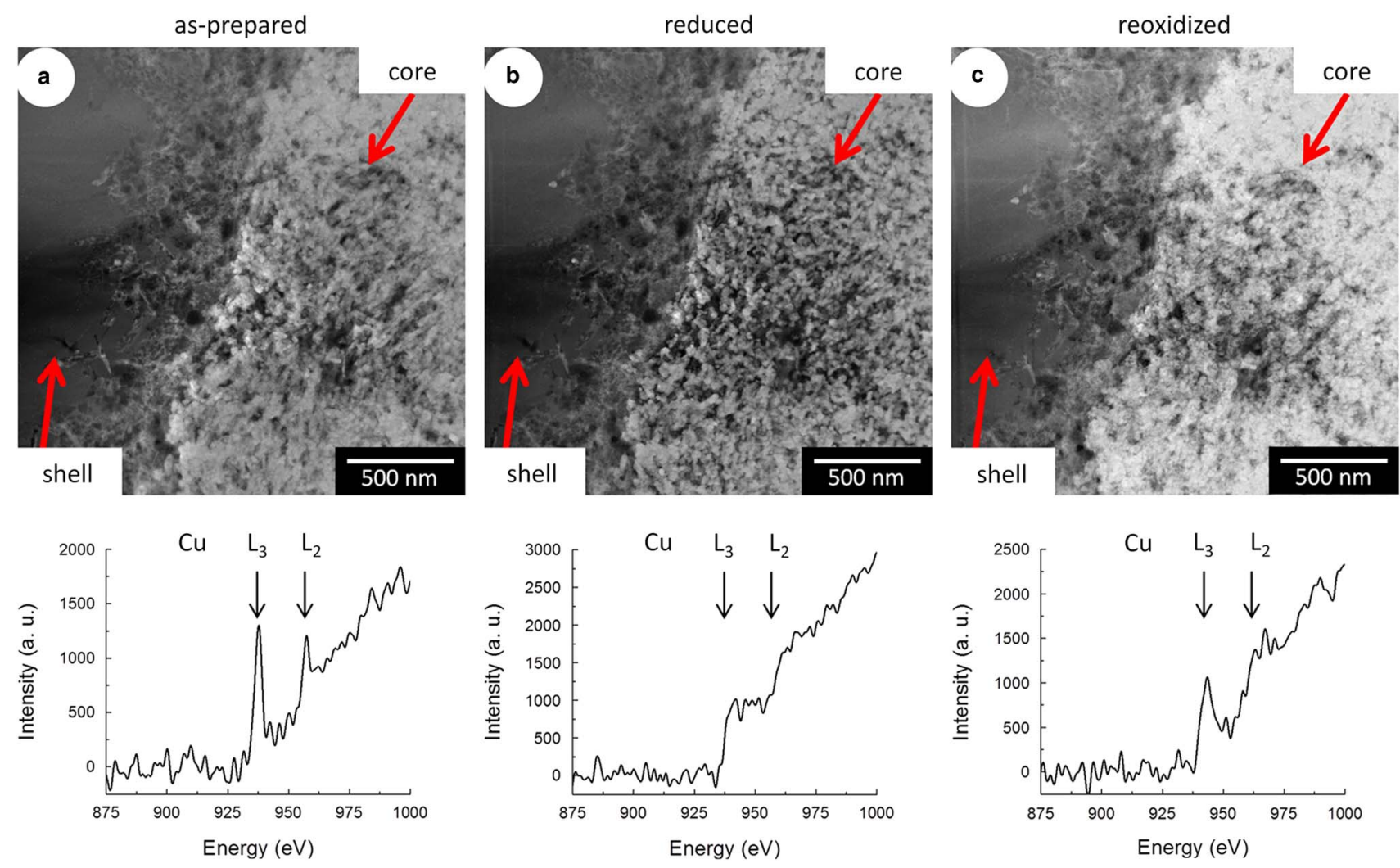

Figure 4. Scanning transmission electron microscopy images and electron energy-loss spectra: (a) as-prepared catalyst studied at room temperature (RT) in $\mathrm{H}_{2}$ by environmental transmission electron microscopy; (b) catalyst under reducing conditions at $250^{\circ} \mathrm{C}$ in $1.1 \mathrm{mbar}^{\circ} \mathrm{H}_{2}$; (c) catalyst under oxidizing conditions at $250^{\circ} \mathrm{C}$ in $3.2 \mathrm{mbar}$ of $\mathrm{O}_{2}$.
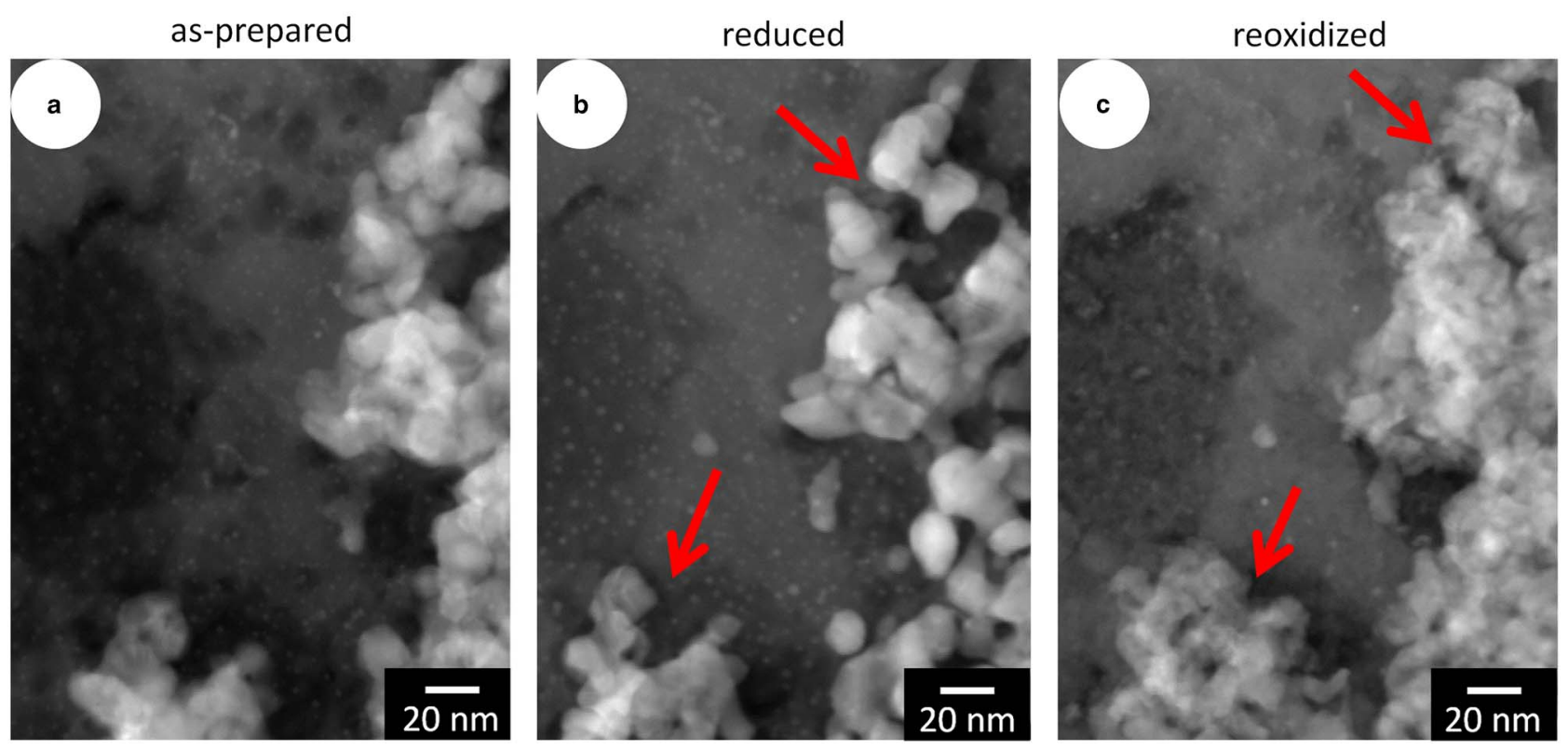

Figure 5. Scanning transmission electron microscopy images presented in Figure $3 c$ under higher magnification: (a) as-prepared catalyst studied at $\mathrm{RT}$ in $\mathrm{H}_{2}$ by environmental transmission electron microscopy; (b) catalyst under reducing conditions at $250^{\circ} \mathrm{C}$ in $1.1 \mathrm{mbar}$ of $\mathrm{H}_{2} ;$ (c) catalyst under oxidizing conditions at $250^{\circ} \mathrm{C}$ in $3.2 \mathrm{mbar}$ of $\mathrm{O}_{2}$. Contrast changes might result from image acquisition.

transparent areas of $\sim 50-\mathrm{nm}$-thick $\mathrm{Si}_{3} \mathrm{~N}_{4}$ membrane. The interface was placed on top of one of these holes, which can be seen in the ptychographic images by the round shape above the blue arrow, indicating the border of the hole. According to the series of phase contrast images obtained by $\mathrm{X}$-ray ptychography, the catalyst remained unchanged on 


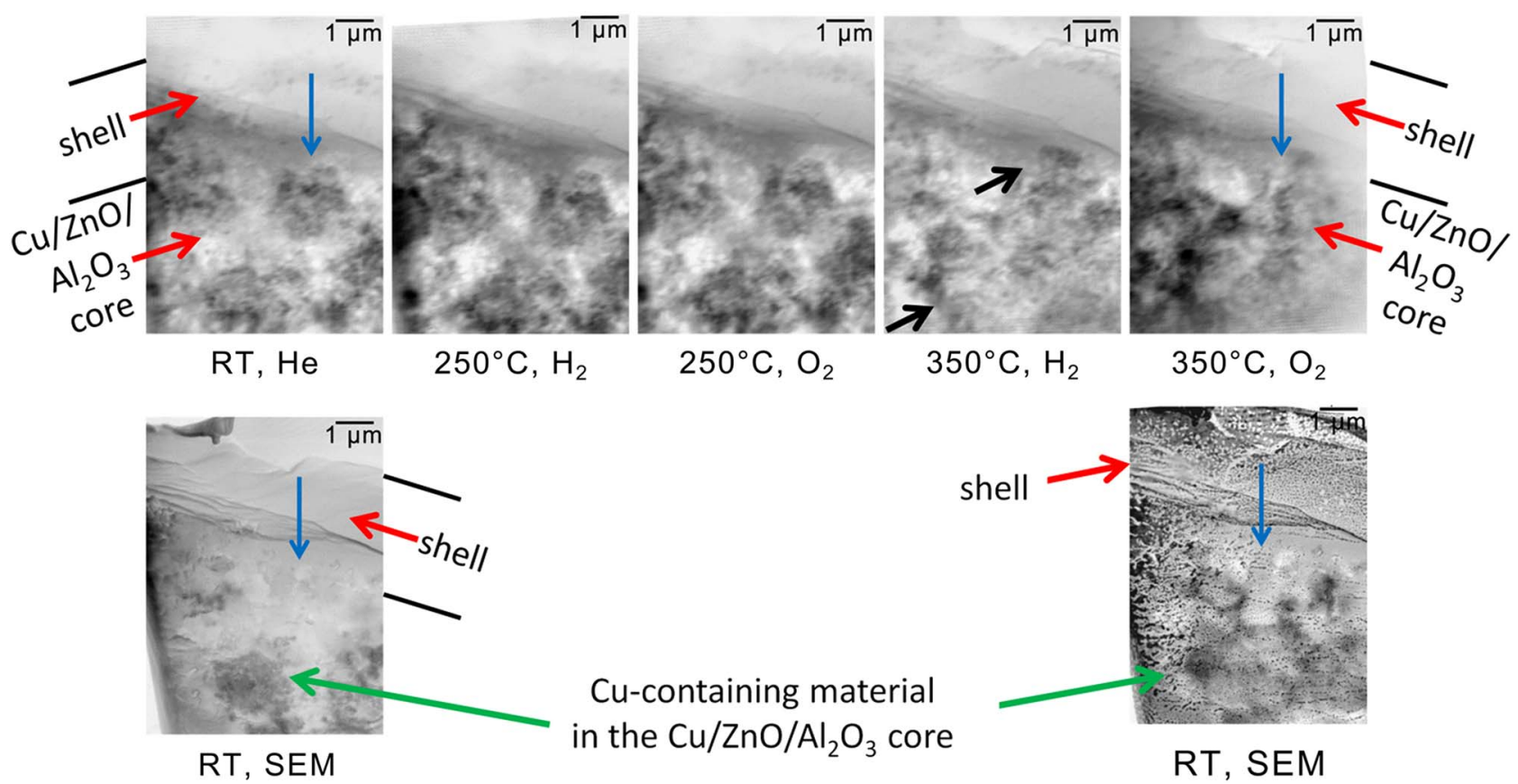

Figure 6. Top: phase contrast images gained by in situ X-ray ptychography under different gas atmospheres and at different temperatures. Bottom: inverted backscattered electron (BSE)-scanning electron microscopy (SEM) images showing material with a high atomic number as darker areas. The BSE-SEM images were recorded ex situ before and after the in situ X-ray ptychography treatment of the sample.

this length scale ( $500 \mathrm{~nm}$ to $1 \mu \mathrm{m}$ ) up to $250^{\circ} \mathrm{C}$ in both reducing and oxidizing atmosphere. Although previous TEM analysis showed small changes in the core material, these cannot be resolved by in situ X-ray ptychography at the current resolution limit, but support the ETEM results on a $100 \mathrm{~nm}$ scale. However, when the temperature was increased to $350^{\circ} \mathrm{C}$, in situ $\mathrm{X}$-ray ptychography revealed visible changes in the core material. Upon moving from reducing to oxidizing atmosphere at $350^{\circ} \mathrm{C}$, further changes seem to occur, including an increase of the phase shift (darkening) and thus projected electron density in certain areas, and a possible migration of material (blue arrow). Some reconstruction artifacts were also observed at the right edge of the frame, which appear out of focus. It should be noted that the image quality is somewhat limited compared with electron microscopy. However, images were recorded at $350^{\circ} \mathrm{C}$ and at ambient pressure and were thus obtained at more realistic environmental conditions than is possible in conventional ETEM, and particularly on a sample which is thicker and therefore more closely resembles a volume of the original catalyst particle.

By SEM-EDX analysis (see Supplementary Fig. 5), it was confirmed that the dark areas indicated by green arrows in Figure 6 contained $\mathrm{Cu}$. As expected from STEM studies, this material should be reduced during $\mathrm{H}_{2}$ treatment and subsequently reoxidized under $\mathrm{O}_{2}$, but as indicated in Figure 5, the changes were previously only visible on a small length scale. However, under ambient pressure using a thicker sample, changes on the $\mu \mathrm{m}$ length scale were observed. This can be either related to the pressure, the sample thickness, or the higher temperature applied in comparison with the treatment in the ETEM. By comparing the phase contrast images (Fig. 6, top) showing the electron density along the transmitted sample volume, with the inverted BSE-SEM images (Fig. 6, bottom or Supplementary Fig. 4) it is evident that the different contrast mechanisms from BSE-SEM and X-ray ptychography reveal complementary information on both the bulk material and the surface, respectively. With X-ray ptychography, changes unrelated to $\mathrm{Cu}$-containing areas in the core were observed. The blue arrow points to an area with high electron density in the ptychographic images, which is not clearly visible in the BSE-SEM images. Therefore it cannot be related to a high- $Z$ species, but might result from thicker or more densely packed material. With the application of complementary EDX analysis, this part of the sample could be attributed to Si (see Supplementary Fig. 5). In fact, the observed changes in this material mean that during in situ treatment at $350^{\circ} \mathrm{C}$, not only the $\mathrm{Cu}$-containing material was affected, but also other regions of the core-shell structure. In this case, parts of the Si containing shell seemed to be changed. However, as depicted in Figure 5 (and Supplementary Fig. 3), the overall core-shell interface itself remained stable, which is critical to maintaining catalyst bifunctionality.

\section{Supplementary Figures 4 and 5}

Supplementary Figures 4 and 5 can be found online. Please visit journals.cambridge.org/jid_MAM. 
a

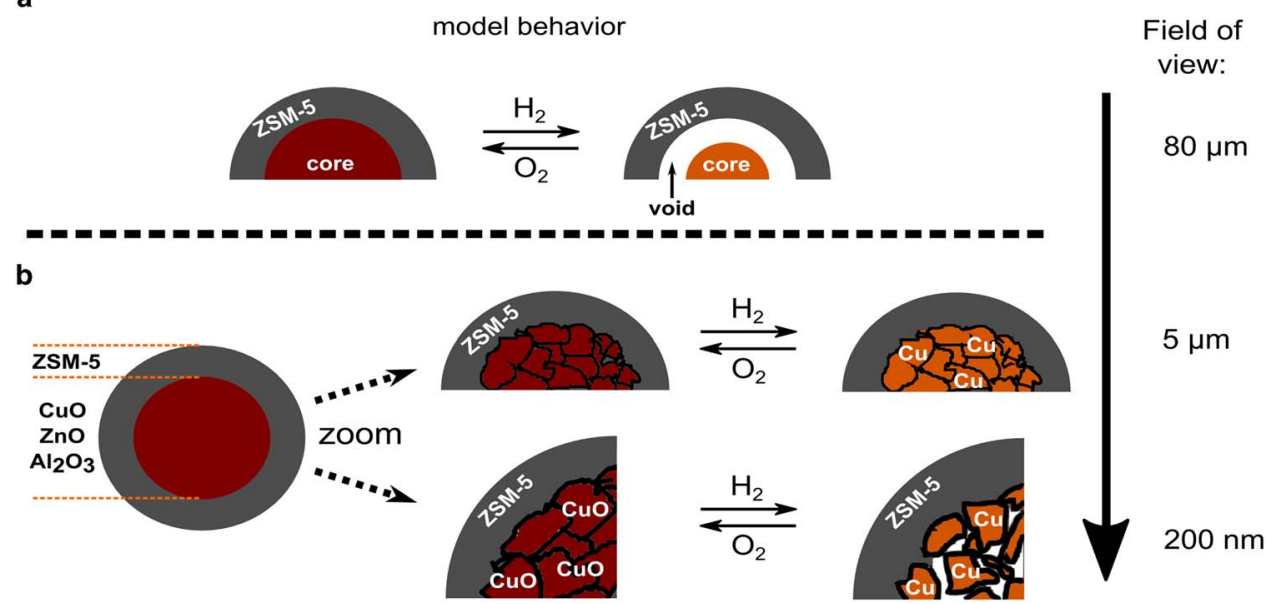

observed behavior

Figure 7. Model of the hierarchically designed core@shell particle showing: (a) the shrinkage of the core assuming a simple model consisting of a $\mathrm{CuO}$ core and a zeolite shell; (b) the observed behavior of the catalyst on the macro-, meso-, and nano-scale.

The results therefore suggest a behavior schematically shown in Figure $7 \mathrm{~b}$. At $250^{\circ} \mathrm{C}$ changes mainly occurred on the nm scale, as observed by TEM and in agreement with earlier work in the literature (Grunwaldt et al., 2000; Andreasen et al., 2006; Holse et al., 2015). According to the in situ TEM and X-ray microscopy results, this does not visibly influence the intermediate structure and only increases the interparticle distances on the nm scale. Under these conditions the bifunctional catalyst remains fully intact on the $\mu \mathrm{m}$ scale. However, at $350^{\circ} \mathrm{C}$ changes which influenced the intermediate length scale of the catalyst were also observed. This might be related to more extensive volume changes caused by reduction/reoxidation or even sintering of the $\mathrm{Cu} / \mathrm{ZnO}$ particles, although the overall core-shell interface still remained unaffected on the $\mu \mathrm{m}$ scale, as illustrated in Figure $6 \mathrm{~b}$. These first changes indicate that the temperature applied might be critical to the catalyst macrostructure and that reductive activation of the catalyst should be performed carefully at low temperatures. This information is crucial for bifunctional core@shell catalysts, as it will influence the surface reactions that take place on the $\mathrm{Cu}$ nanoparticles in the core and the heat/mass transport effects which play a role on the $\mu \mathrm{m}$ scale, i.e. diffusion and reaction in the acidic zeolite (Matera \& Reuter, 2012; Grunwaldt et al., 2013; Güttel, 2015).

The present study indicates the importance of performing in situ studies on different length scales in order to characterize hierarchically designed bifunctional catalysts. In addition, this study shows the potential value of complementary electron microscopy and hard X-ray ptychography. Although the complementarity of X-ray and electron microscopy has often been discussed (Thomas \& Hernandez-Garrido, 2009; de Groot et al., 2010; Grunwaldt \& Schroer 2010; Buurmans \& Weckhuysen, 2012; Andrews \& Weckhuysen, 2013; Grunwaldt et al., 2013), the methods were only rarely applied to study the same catalytic system (Basile et al., 2010) or even the same catalyst samples (Li et al., 2015b; Baier et al., 2016a). In particular, complementary in situ studies on the same catalytic systems are missing, since this requires the design of special in situ cells and careful sample preparation. Nevertheless, in situ or quasi in situ studies are important to draw more solid conclusions, as the statistics would be limited in multiscale approaches based on ex situ studies (Hofmann et al., 2015).

Although ETEM can give information on the structural changes on the nanoscale, SEM and X-ray microscopy can probe larger areas. SEM is more surface sensitive, and in combination with backscattering contrast strongly sensitive to the atomic number. X-ray ptychography on the other hand offers information on the electron density along the transmitted beam path through the sample, in a similar manner to TEM. However, as demonstrated here for thicker samples, X-ray ptychography offers a similar resolution to TEM, but with higher contrast (see Supplementary Fig. 6). Hard X-ray ptychography furthermore allows combination with resonant measurements to provide chemical contrast (Beckers et al., 2011; Hoppe et al., 2013), as demonstrated with scanning transmission X-ray microscopy (de Smit et al., 2008; Gonzalez-Jimenez et al., 2012; Meirer et al., 2015). Alternatively, as depicted in Figure 5, TEM analysis offers high resolution and the possibility to be combined with spectroscopy (EDX or EELS) and diffraction (selected angle electron diffraction). Nevertheless, for 3D samples studied by two-dimensional transmission imaging, it has to be taken into account that only projections of the electron density are obtained, which requires the need for non-invasive tomographic studies to gain 3D information (Friedrich et al., 2009; Dierolf et al., 2010; Meirer et al., 2011; Holler et al., 2014; da Silva et al., 2015; de Winter et al., 2016). This would also avoid the invasive sample preparation method required 
to obtain thin sections for electron microscopy, which could potentially alter the catalyst structure and behavior. For the purposes of studying reductive activation/reoxidation processes, the sample preparation is not expected to influence the catalyst behavior. However, this requires attention before studying catalysts under reaction atmospheres.

\section{Supplementary Figure 6}

Supplementary Figure 6 can be found online. Please visit journals.cambridge.org/jid_MAM.

The combination of approaches presented here, i.e. in situ hard X-ray ptychography and ETEM analysis, allows complementary information to be obtained on hierarchically designed structures, which should further be combined with in situ tomographic imaging (Price et al., 2015a) for a holistic understanding of the overall structure. The multiscale in situ imaging approach pioneered here for assessing the stability of structure dependent materials such as hierarchically designed core@shell catalysts should be furthered, as it will also be excellently suited for investigating related questions. For example: the stability of particles in reactors such as fluidized bed reactors (stabilizing shell) (Kalirai et al., 2015; Meirer et al., 2015); the homogeneity, structure and connectivity in shell impregnated catalysts (Grunwaldt et al., 2009) and other core@shell catalysts (Li et al., 2010; Lee et al., 2012); structural and compositional changes under reaction conditions for bifunctional Fischer-Tropsch catalysts (Kruse et al., 2015); or the stability of battery or fuel cell materials (Kee et al., 2008; Ulvestad et al., 2014; Simonsen et al., 2015). In all these examples, the structure and stability of the material is critically related to the function and a rational hierarchical design. An in situ characterization methodology applied at various length scales and under steadily more realistic conditions is expected to become important in the near future.

\section{CONCLUSIONS}

In the present work, the complementary use of in situ hard $\mathrm{X}$-ray ptychography and electron microscopy was evaluated to study the stability of a core@shell catalyst in a hierarchical manner at different length scales. Both activation in hydrogen atmosphere and reoxidation under synthetic air were selected as model conditions for this first case study. ETEM performed on a thin section of the catalyst under reduced pressure revealed a stable core-shell interface at $250^{\circ} \mathrm{C}$, although reduction of the $\mathrm{Cu}$-containing core material led to a shrinkage of the particles on the nm scale. Complementary in situ X-ray ptychography allowed studying the system not only under model conditions, but also at atmospheric pressure and on a thicker sample. Whereas at $250^{\circ} \mathrm{C}$ the core-shell interface was found to be stable, further heating to $350^{\circ} \mathrm{C}$ indicated changes on the $\mu \mathrm{m}$ scale. According to complementary SEM-EDX analysis not only the
$\mathrm{Cu}$-containing core material was affected by the treatment, but also parts of the shell material were rearranged. Despite strong changes in the core material, the overall coreshell interface of the catalyst remained stable, which is critical to maintaining the bifunctional operation of such catalysts.

The results obtained in this study support that complementary information from electron microscopy and $\mathrm{X}$-ray microscopy can be used to study working catalytic systems, covering different length scales and different pressure regimes. In situ X-ray ptychography with better than $30 \mathrm{~nm}$ spatial resolution can now start to bridge the gap between high-resolution TEM under idealized conditions, and hard X-ray imaging techniques under more realistic conditions, although simpler sample preparation and improved in situ cells are still areas which require further development. In future, such studies should be performed nondestructively on sections and complete core@shell particles by tomography to fully support the so-called product design of catalysts in chemical engineering.

\section{ACKNOWLEDGMENTS}

The authors thank the "Stiftung der Deutschen Wirtschaft" (S.B.) for a PhD grant. Moreover, the authors also acknowledge the BMBF projects "X-ray microscopy" (05K10VK1/ 05K10OD1) and "Nanoscopy" (05K13VK2/05K13OD4), the virtual institute VI-403 "In-situ Nano Imaging of Biological and Chemical Processes", and the Helmholtz Research Program "Science and Technology of Nanosystems" as well as the Danish National Research Foundation's Center for Individual Nanoparticle Functionality (DNRF54) for financial support. The A.P. Møller and Chastine Mc-kinney Møller Foundation is gratefully acknowledged for its contribution towards establishment of the Center for Electron Nanoscopy at the Technical University of Denmark. M.K. and W.S. would also like to thank the German Research Foundation for their funding in the frame of the priority program SPP 1570 "Porous Media with Defined Pore Structure in Process Engineering - Modelling, Application, Synthesis" (grant numbers SCHW 478/23-1 to 478/23-3). In addition, the authors acknowledge the KNMF, a Helmholtz Research Infrastructure at KIT, for the opportunity to use the FIB-SEM. Finally, the authors thank DESY for allocation of beamtime at P06 and the beamline team, especially Dr. Gerald Falkenberg and Maria Scholz, for their help during the beamtime.

\section{REFERENCES}

Abu-Dahrieh, J., Rooney, D., Goguet, A. \& Saih, Y. (2012). Activity and deactivation studies for direct dimethyl ether synthesis using $\mathrm{CuO}-\mathrm{ZnO}-\mathrm{Al}_{2} \mathrm{O}_{3}$ with $\mathrm{NH}(4) \mathrm{ZSM}-5$, HZSM-5 or gamma- $\mathrm{Al}_{2} \mathrm{O}_{3}$. Chem Eng J 203, 201-211.

Ahmad, R., Schrempr, D., Behrens, S., Sauer, J., Doering, M. \& ARnold, U. (2014). Zeolite-based bifunctional catalysts for the single step synthesis of dimethyl ether from CO-rich synthesis gas. Fuel Process Technol 121, 38-46. 
Allahyari, S., Haghighi, M., Ebadi, A. \& SaeEdi, H.Q. (2014). Direct synthesis of dimethyl ether as a green fuel from syngas over nanostructured $\mathrm{CuO}-\mathrm{ZnO}-\mathrm{Al}_{2} \mathrm{O}_{3} / \mathrm{HZSM}-5$ catalyst: Influence of irradiation time on nanocatalyst properties and catalytic performance. J Power Sources 272, 929-939.

Allard, L.F., FlytZani-Stephanopoulos, M. \& Overbury, S.H. (2009). A novel heating technology for ultra-high resolution imaging in electron microscopes. Microsc Today 17(4), 50-55.

Andreasen, J.W., Rasmussen, F.B., Helveg, S., Molenbroek, A., Stahl, K., Nielsen, M.M. \& Feidenhans'L, R. (2006). Activation of a $\mathrm{Cu} / \mathrm{ZnO}$ catalyst for methanol synthesis. J Appl Crystallogr 39(2), 209-221.

Andrews, J.C. \& WeCKhuysen, B.M. (2013). Hard X-ray spectroscopic nano-imaging of hierarchical functional materials at work. ChemPhysChem 14(16), 3655-3666.

Azizi, Z., Rezaeimanesh, M., Tohidian, T. \& Rahimpour, M.R. (2014). Dimethyl ether: A review of technologies and production challenges. Chem Eng Process 82, 150-172.

Baier, S., Damsgaard, C.D., Scholz, M., Benzi, F., Rochet, A., Hoppe, R., Scherer, T., Shi, J., Wittstock, A., Weinhausen, B., WAGNer, J.B., Schroer, C.G. \& Grunwaldt, J.-D. (2016a). In situ ptychography of heterogeneous catalysts using hard X-rays: High resolution imaging at ambient pressure and elevated temperature. Microsc Microanal 22(1), 178-188.

Baier, S., Wittstock, A., Damsgaard, C.D., Diaz, A., Reinhardt, J., Damsgaard, C.D., Benzi, F., Shi, J., Scherer, T., Wang, D., Schroer, C.G. \& Grunwaldt, J.-D. (2016b). Influence of gas atmosphere and ceria layers on the stability of nanoporous gold studied by environmental electron microscopy and in situ ptychography. RSC Adv 6(86), 83031-83043.

BaO, J., He, J., Zhang, Y., Yoneyama, Y. \& Tsubaki, N. (2008). A core/ shell catalyst produces a spatially confined effect and shape selectivity in a consecutive reaction. Angew Chem 120(2), 359-362.

BaO, J., Yang, G., OKada, C., Yoneyama, Y. \& Tsubaki, N. (2011). $\mathrm{H}$-type zeolite coated iron-based multiple-functional catalyst for direct synthesis of middle isoparaffins from syngas. Appl Catal A Gen 394(1), 195-200.

Basile, F., Benito, P., Bugani, S., De Nolf, W., Fornasari, G., Janssens, K., Morselli, L., Scavetta, E., Tonelli, D. \& Vaccari, A. (2010). Combined use of synchrotron-radiation-based imaging techniques for the characterization of structured catalysts. $A d v$ Funct Mater 20(23), 4117-4126.

Beckers, M., Senkbeil, T., Gorniak, T., Reese, M., Giewekemeyer, K., Gleber, S.-C., Salditt, T. \& Rosenhahn, A. (2011). Chemical contrast in soft X-ray ptychography. Phys Rev Lett 107(20), 208101.

BuUrmans, I.L.C. \& WeCKhuysen, B.M. (2012). Heterogeneities of individual catalyst particles in space and time as monitored by spectroscopy. Nat Chem 4(11), 873-886.

Cats, K.H., Gonzalez-Jimenez, I.D., Liu, Y., Nelson, J., van Campen, D., Meirer, F., van der Eerden, A.M.J., de Groot, F.M.F., Andrews, J.C. \& WeCKhuYsen, B.M. (2013). X-ray nanoscopy of cobalt FischerTropsch catalysts at work. Chem Commun 49(41), 4622-4624.

Creemer, J.F., Helveg, S., Kooyman, P.J., Molenbroek, A.M., Zandbergen, H.W. \& SARro, P.M. (2010). A MEMS reactor for atomic-scale microscopy of nanomaterials under industrially relevant conditions. J Microelectromech Syst 19(2), 254-264.

da Silva, J.C., Mader, K., Holler, M., Haberthuer, D., Diaz, A., Guizar-Sicairos, M., Cheng, W.-C., Shu, Y., Raabe, J., Menzel, A. \& van BoKhoven, J.A. (2015). Assessment of the 3D pore structure and individual components of preshaped catalyst bodies by X-ray imaging. ChemCatChem 7(3), 413-416.
Dahmen, N., Henrich, E., Dinjus, E. \& Weirich, F. (2012). The Bioliq ${ }^{\circledR}$ bioslurry gasification process for the production of biosynfuels, organic chemicals, and energy. Energy Sustain Soc 2(1), 1-44.

de Groot, F.M.F., de Smit, E., van Schooneveld, M.M., Aramburo L.R. \& WeCKHUYSEN, B.M. (2010). In-situ scanning transmission $\mathrm{X}$-ray microscopy of catalytic solids and related nanomaterials. ChemPhysChem 11(5), 951-962.

de Smit, E., Swart, I., Creemer, J.F., Hoveling, G.H., Gilles, M.K., Tyliszczak, T., Kooyman, P.J., Zandbergen, H.W., Morin, C., Weckhuysen, B.M. \& DE Groot, F.M.F. (2008). Nanoscale chemical imaging of a working catalyst by scanning transmission X-ray microscopy. Nature 456(7219), 222-239.

de Winter, D.A.M., Meirer, F. \& Weckhuysen, B.M. (2016). FIBSEM tomography probes the mesoscale pore space of an individual catalytic cracking particle. ACS Catal 6(5), 3158-3167.

Dierolf, M., Menzel, A., Thibault, P., Schneider, P., Kewish, C.M., Wepf, R., Bunk, O. \& Pfeiffer, F. (2010). Ptychographic X-ray computed tomography at the nanoscale. Nature 467(7314), 436-439.

Ding, W., Klumpe, M., Lee, S., Reuss, S., Al-Thabaiti, S.A., Pfeifer, P., Schwieger, W. \& Dittmeyer, R. (2015). Simulation of one-stage dimethyl ether synthesis over a core-shell catalyst. Chem Ing Tech 87(6), 702-712.

Falcone, R., Jacobsen, C., Kirz, J., Marchesini, S., Shapiro, D. \& SPENCE, J. (2011). New directions in X-ray microscopy. Contemp Phys 52(4), 293-318.

Friedrich, H., de Jongh, P.E., Verkleij, A.J. \& de Jong, K.P. (2009). Electron tomography for heterogeneous catalysts and related nanostructured materials. Chem Rev 109(5), 1613-1629.

Garcia-Trenco, A. \& Martinez, A. (2015). A rational strategy for preparing $\mathrm{Cu}-\mathrm{ZnO} / \mathrm{H}-\mathrm{ZSM}-5$ hybrid catalysts with enhanced stability during the one-step conversion of syngas to dimethyl ether (DME). Appl Catal A Gen 493, 40-49.

Garcia-Trenco, A., Vidal-Moya, A. \& Martinez, A. (2012). Study of the interaction between components in hybrid $\mathrm{CuZnAl} /$ HZSM-5 catalysts and its impact in the syngas-to-DME reaction. Catal Today 179(1), 43-51.

Ge, Q.J., Huang, Y.M., Qiu, F.Y. \& LI, S.B. (1998). Bifunctional catalysts for conversion of synthesis gas to dimethyl ether. Appl Catal A Gen 167(1), 23-30.

Gentzen, M., Habicht, W., Doronkin, D.E., Grunwaldt, J.D., Sauer, J. \& BeHRENS, S. (2016). Bifunctional hybrid catalysts derived from $\mathrm{Cu} / \mathrm{Zn}$-based nanoparticles for single-step dimethyl ether synthesis. Catal Sci Technol 6(4), 1054-1063.

Gonzalez-Jimenez, I.D., Cats, K., Davidian, T., Ruitenbeek, M., Meirer, F., Liu, Y., Nelson, J., Andrews, J.C., Pianetta, P., de Groot, F.M.F. \& Weckhuysen, B.M. (2012). Hard X-ray nanotomography of catalytic solids at work. Angew Chem Int Ed 51(48), 11986-11990.

Goris, B., Bals, S., Van den Broek, W., Carbó-Argibay, E., Gómez-Graña, S., Liz-Marzán, L.M. \& Van Tendeloo, G (2012). Atomic-scale determination of surface facets in gold nanorods. Nat Mater 11(11), 930-935.

Grunwaldt, J.-D., Kimmerle, B., Baiker, A., Boye, P., Schroer, C.G., Glatzel, P., Borca, C.N. \& Beckmann, F. (2009). Catalysts at work: From integral to spatially resolved X-ray absorption spectroscopy. Catal Today 145(3-4), 267-278.

Grunwaldt, J.-D., Molenbroek, A.M., Topsoe, N.Y., Topsoe, H. \& Clausen, B.S. (2000). In situ investigations of structural changes in $\mathrm{Cu} / \mathrm{ZnO}$ catalysts. J Catal 194(2), 452-460. 
Grunwaldt, J.-D. \& Schroer, C.G. (2010). Hard and soft X-ray microscopy and tomography in catalysis: Bridging the different time and length scales. Chem Soc Rev 39(12), 4741-4753.

Grunwaldt, J.-D., Wagner, J.B. \& Dunin-Borkowski, R.E. (2013). Imaging catalysts at work. A hierarchical approach from the macro- to the meso- and nano-scale. ChemCatChem 5, 62-80.

GütTEL, R. (2015). Structuring of reactors and catalysts on multiple scales: Potential and limitations for Fischer-Tropsch synthesis. Chem Ing Tech 87(6), 694-701.

Hansen, P.L., Wagner, J.B., Helveg, S., Rostrup-Nielsen, J.R., Clausen, B.S. \& Topsoe, H. (2002). Atom-resolved imaging of dynamic shape changes in supported copper nanocrystals. Science 295(5562), 2053-2055.

Hansen, T.W. \& Wagner, J.B. (2012). Environmental transmission electron microscopy in an aberration-corrected environment. Microsc Microanal 18(4), 684-690.

Hayer, F., Bakhtiary-Davijany, H., Myrstad, R., Holmen, A., Pfeifer, P. \& Venvik, H.J. (2011). Synthesis of dimethyl ether from syngas in a microchannel reactor-Simulation and experimental study. Chem Eng J 167(2), 610-615.

Hofmann, G., Rochet, A., Ogel, E., Casapu, M., Ritter, S., Ogurreck, M. \& Grunwaldt, J.-D. (2015). Aging of a Pt/ $/ \mathrm{Al}_{2} \mathrm{O}_{3}$ exhaust gas catalyst monitored by quasi in situ X-ray micro computed tomography. RSC Adv 5(9), 6893-6905.

Holler, M., Diaz, A., Guizar-Sicairos, M., Karvinen, P., Farm, E., Harkonen, E., Ritala, M., Menzel, A., Raabe, J. \& Bunk, O. (2014). X-ray ptychographic computed tomography at $16 \mathrm{~nm}$ isotropic 3D resolution. Sci Rep 4, 3857.

Holse, C., Elkjaer, C.F., Nierhoff, A., Sehested, J., Chorkendorff, I., Helveg, S. \& Nielsen, J.H. (2015). Dynamic behavior of CuZn nanoparticles under oxidizing and reducing conditions. J Phys Chem C 119(5), 2804-2812.

Hoppe, R., Reinhardt, J., Hofmann, G., Patommel, J., Grunwaldt, J.D., Damsgatrd, C.D., Wellenreuther, G., Falkenberg, G. \& SCHroER, C.G. (2013). High-resolution chemical imaging of gold nanoparticles using hard x-ray ptychography. Appl Phys Lett 102 (20), 203104-1-203104-5.

Høydalsvik, K., Floystad, J.B., Zhao, T., Esmaeili, M., Diaz, A., Andreasen, J.W., Mathiesen, R.H., Ronning, M. \& Breiby, D.W. (2014). In situ X-ray ptychography imaging of high-temperature $\mathrm{CO}_{2}$ acceptor particle agglomerates. Appl Phys Lett 104(24), 24109-1-24109-5.

Huang, Y., Zhou, X., Yin, M., Liu, C. \& XING, W. (2010). Novel PdAu@Au/C core-shell catalyst: Superior activity and selectivity in formic acid decomposition for hydrogen generation. Chem Mater 22(18), 5122-5128.

Kalirai, S., Boesenberg, U., Falkenberg, G., Meirer, F. \& WeCKhuYsen, B.M. (2015). X-ray Fluorescence tomography of aged fluid-catalytic-cracking catalyst particles reveals insight into metal deposition processes. ChemCatChem 7(22), 3674-3682.

Kee, R.J., Zhu, H., Sukeshini, A.M. \& Jackson, G.S. (2008). Solid oxide fuel cells: Operating principles, current challenges, and the role of syngas. Combust Sci Technol 180(6), 1207-1244.

Kruse, N., Machoke, A.G., Schwieger, W. \& Güttel, R. (2015). Nanostructured encapsulated catalysts for combination of Fischer-Tropsch synthesis and hydroprocessing. Chem CatChem 7(6), 1018-1022.

Kuld, S., Thorhauge, M., Falsig, H., Elkjaer, C.F., Helveg, S., Chorkendorff, I. \& Sehested, J. (2016). Quantifying the promotion of $\mathrm{Cu}$ catalysts by $\mathrm{ZnO}$ for methanol synthesis. Science 352(6288), 969-974.
LeE, H., KIM, S., LeE, D.-W. \& LeE, K.-Y. (2011). Direct synthesis of hydrogen peroxide from hydrogen and oxygen over a $\mathrm{Pd}$ core-silica shell catalyst. Catal Commun 12(11), 968-971.

Lee, H.C., Potapova, Y. \& Lee, D. (2012). A core-shell structured, metal-ceramic composite-supported Ru catalyst for methane steam reforming. J Power Sources 216, 256-260.

LI, J., PAN, X. \& BAO, X. (2015a). Direct conversion of syngas into hydrocarbons over a core-shell Cr- $\mathrm{Zn} @ \mathrm{SiO}_{2} @ S A P O-34$ catalyst. Chinese J Catal 36(7), 1131-1135.

LI, Q., XIN, C. \& LIAN, P. (2012). The synthesis and application of $\mathrm{CuO}-\mathrm{ZnO} / \mathrm{HZSM}-5$ catalyst with core-shell structure. Pet Sci Technol 30(21), 2187-2195.

Li, Y., YaO, L., Song, Y., LiU, S., ZhaO, J., Ji, W. \& Au, C.-T. (2010). Core-shell structured microcapsular-like $\mathrm{Ru@SiO} 2$ reactor for efficient generation of $\mathrm{CO}_{\mathrm{x}}$-free hydrogen through ammonia decomposition. Chem Commun 46(29), 5298-5300.

Li, Y., Zakharov, D., Zhao, S., Tappero, R., Jung, U., Elsen, A., Baumann, P., Nuzzo, R.G., Stach, E.A. \& Frenkel, A.I. (2015b). Complex structural dynamics of nanocatalysts revealed in Operando conditions by correlated imaging and spectroscopy probes. Nat Commun 6, 7583.

Maiden, A.M. \& Rodenburg, J.M. (2009). An improved ptychographical phase retrieval algorithm for diffractive imaging. Ultramicroscopy 109(10), 1256-1262.

Markötter, H., Manke, I., KrÜger, P., Arlt, T., Haussmann, J., Klages, M., Riesemeier, H., Hartnig, C., Scholta, J. \& Banhart, J. (2011). Investigation of $3 \mathrm{D}$ water transport paths in gas diffusion layers by combined in-situ synchrotron X-ray radiography and tomography. Electrochem Commun 13(9), 1001-1004.

Matera, S. \& Reuter, K. (2012). When atomic-scale resolution is not enough: Spatial effects on in situ model catalyst studies. J Catal 295, 261-268.

Meirer, F., Cabana, J., Liu, Y., Mehta, A., Andrews, J.C. \& Pianetta, P. (2011). Three-dimensional imaging of chemical phase transformations at the nanoscale with full-field transmission X-ray microscopy. J Synchrotron Radiat 18(5), 773-781.

Meirer, F., Kalirai, S., Weker, J.N., Liu, Y., Andrews, J. \& Weckhuysen, B. (2015). Agglutination of single catalyst particles during fluid catalytic cracking as observed by X-ray nanotomography. Chem Commun 51(38), 8097-8100.

NG, K.M., Gani, R. \& Dam-Johansen, K. (2007). Chemical Product Design: Towards a Perspective through Case Studies, vol. 23. Amsterdam: Elsevier Science.

Nie, R., Lei, H., PAN, S., WANG, L., Fei, J. \& Hou, Z. (2012). Core-shell structured $\mathrm{CuO}-\mathrm{ZnO} @ \mathrm{H}-\mathrm{ZSM}-5$ catalysts for $\mathrm{CO}$ hydrogenation to dimethyl ether. Fuel 96(1), 419-425.

Phienluphon, R., Pinkaew, K., Yang, G., Li, J., Wei, Q., Yoneyama, Y., Vitidsant, T. \& Tsubaki, N. (2015). Designing core $(\mathrm{Cu} / \mathrm{ZnO} /$ $\mathrm{Al}_{2} \mathrm{O}_{3}$ )-shell (SAPO-11) zeolite capsule catalyst with a facile physical way for dimethyl ether direct synthesis from syngas. Chem Eng J 270, 605-611.

Pinkaew, K., Yang, G., Vitidsant, T., Jin, Y., Zeng, C., Yoneyama, Y. \& TSUBAKI, N. (2013). A new core-shell-like capsule catalyst with SAPO-46 zeolite shell encapsulated $\mathrm{Cr} / \mathrm{ZnO}$ for the controlled tandem synthesis of dimethyl ether from syngas. Fuel 111, 727-732.

Prasad, P.S.S., BAe, J.W., Kang, S.-H., Lee, Y.-J. \& Jun, K.-W. (2008). Single-step synthesis of DME from syngas on $\mathrm{Cu}-\mathrm{ZnO}-\mathrm{Al}_{2} \mathrm{O}_{3}$ / zeolite bifunctional catalysts: The superiority of ferrierite over the other zeolites. Fuel Process Technol 89(12), 1281-1286. 
Price, S., Ignatyev, K., Geraki, K., Basham, M., Filik, J., Vo, N., Witte, P., Beale, A. \& Mosselmans, J. (2015a). Chemical imaging of single catalyst particles with scanning $\mu$-XANES-CT and

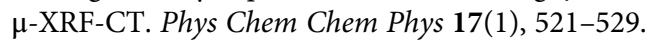

Price, S.W.T., Geraki, K., Ignatyev, K., Witte, P.T., Beale, A.M. \& Mosselmans, J.F.W. (2015b). In situ microfocus chemical computed tomography of the composition of a single catalyst particle during hydrogenation of nitrobenzene in the liquid phase. Angew Chem Int Ed 54(34), 9886-9889.

Sankar, M., Dimitratos, N., Miedziak, P.J., Wells, P.P., Kiely, C.J. \& Hutchings, G.J. (2012). Designing bimetallic catalysts for a green and sustainable future. Chem Soc Rev 41(24), 8099-8139.

Schroer, C.G., Boye, P., Feldkamp, J.M., Patommel, J., Schropp, A., Samberg, D., Stephan, S., Burghammer, M., Schoder, S., Riekel, C., Lengeler, B., Falkenberg, G., Wellenreuther, G., Kuhlmann, M., Frahm, R., Lutzenkirchen-Hecht, D. \& Schroeder, W.H. (2010). Hard X-ray microscopy with elemental, chemical, and structural contrast. Acta Phys Polonica A 117(2), 357-368.

Schropp, A., Hoppe, R., Patommel, J., Samberg, D., Seiboth, F., Stephan, S., Wellenreuther, G., Falkenberg, G. \& Schroer, C.G. (2012). Hard X-ray scanning microscopy with coherent radiation: Beyond the resolution of conventional $\mathrm{x}$-ray microscopes. Appl Phys Lett 100(25), 253112.

Schwieger, W., Klumpp, M., Al-Thabaiti, S.A. \& Hartmann, M. (2016). Präparationsprinzipien mikroporöser Materialien: Vom building block zum hierarchisch aufgebauten porösen System. Chem Ing Tech 88(3), 237-257.

Simonsen, S.B., Agersted, K., Hansen, K.V., Jacobsen, T., Wagner, J.B., Hansen, T.W. \& KunN, L.T. (2015). Environmental TEM study of the dynamic nanoscaled morphology of NiO/YSZ during reduction. Appl Catal A Gen 489, 147-154.

Stach, E.A., Li, Y., Zhao, S., Gamalski, A., Zakharov, D., Tappero, R., Chen-Weigart, K., Thieme, J., Jung, U. \& Elsen, A. (2015). Characterizing working catalysts with correlated electron and photon probes. Microsc Microanal 21(Suppl 3), 563-564.

Studt, F., Behrens, M., Kunkes, E.L., Thomas, N., Zander, S., Tarasov, A., Schumann, J., Frei, E., Varley, J.B., Abild-Pedersen, F., Norskov, J.K. \& SCHLOGL, R. (2015). The mechanism of CO and $\mathrm{CO}_{2}$ hydrogenation to methanol over $\mathrm{Cu}$-based catalysts. ChemCatChem 7(7), 1105-1111.

Sun, B., Yu, G., Lin, J., Xu, K., Pei, Y., Yan, S., Qiao, M., Fan, K., Zhang, X. \& Zong, B. (2012). A highly selective Raney Fe@HZSM-5 Fischer-Tropsch synthesis catalyst for gasoline production: One-pot synthesis and unexpected effect of zeolites. Catal Sci Technol 2(8), 1625-1629.

Thomas, J.M. \& Hernandez-Garrido, J.-C. (2009). Probing solid catalysts under operating conditions: Electrons or X-rays? Angew Chem Int Ed 48(22), 3904-3907.
Ulvestad, A., Singer, A., Cho, H.-M., Clark, J.N., Harder, R., Maser, J., Meng, Y.S. \& Shpyrko, O.G. (2014). Single particle nanomechanics in operando batteries via lensless strain mapping. Nano Lett 14(9), 5123-5127.

van Heel, M. \& Schatz, M. (2005). Fourier shell correlation threshold criteria. J Struct Biol 151(3), 250-262.

Vila-Comamala, J., Diaz, A., Guizar-Sicairos, M., Mantion, A., Kewish, C.M., Menzel, A., Bunk, O. \& David, C. (2011). Characterization of high-resolution diffractive X-ray optics by ptychographic coherent diffractive imaging. Opt Express 19(22), 21333-21344.

WANG, Y., Wang, W., Chen, Y., MA, J. \& LI, R. (2014). Synthesis of dimethyl ether from syngas over core-shell structure catalyst $\mathrm{CuO}-\mathrm{ZnO}-\mathrm{Al}_{2} \mathrm{O}_{3} @ \mathrm{SiO}_{2}-\mathrm{Al}_{2} \mathrm{O}_{3}$. Chem Eng J 250, 248-256.

WANG, Y., WANG, W., Chen, Y., Ma, J., Zheng, J. \& Li, R. (2013). Core-shell catalyst CuO- $\mathrm{ZnO}-\mathrm{Al}_{2} \mathrm{O}_{3} @ \mathrm{Al}_{2} \mathrm{O}_{3}$ for dimethyl ether synthesis from syngas. Chem Lett 42(4), 335-337.

Wecknuysen, B.M. (2009). Chemical imaging of spatial heterogeneities in catalytic solids at different length and time scales. Angew Chem Int Ed 48(27), 4910-4943.

Xu, L., Peng, H.-G., Zhang, K., Wu, H., Chen, L., Liu, Y. \& Wu, P. (2013). Core-shell-structured titanosilicate as a robust catalyst for cyclohexanone ammoximation. ACS Catal 3(1), 103-110.

Yang, G., He, J., Yoneyama, Y., Tan, Y., Han, Y. \& Tsubaki, N. (2007). Preparation, characterization and reaction performance of H-ZSM-5/cobalt/silica capsule catalysts with different sizes for direct synthesis of isoparaffins. Appl Catal A Gen 329, 99-105.

Yang, G., Tsubaki, N., Shamoto, J., Yoneyama, Y. \& Zhang, Y. (2010). Confinement effect and synergistic function of $\mathrm{H}-\mathrm{ZSM}-5 / \mathrm{Cu}-\mathrm{ZnO}-\mathrm{Al}_{2} \mathrm{O}_{3}$ capsule catalyst for one-step controlled synthesis. J Am Chem Soc 132(23), 8129-8136.

YanG, G., Xing, C., Hirohama, W., Jin, Y., Zeng, C., Suehiro, Y., Wang, T., Yoneyama, Y. \& Tsubaki, N. (2013). Tandem catalytic synthesis of light isoparaffin from syngas via Fischer-Tropsch synthesis by newly developed core-shell-like zeolite capsule catalysts. Catal Today 215, 29-35.

YAnG, X.-Y., Sun, S., Ding, J.-J., Zhang, Y., Zhang, M.-M., GaO, C. \& $\mathrm{BAO}, J$. (2012). Preparation, structure and performance of $\mathrm{CuO}-\mathrm{ZnO}-\mathrm{Al}_{2} \mathrm{O}_{3} / \mathrm{HZSM}-5$ core-shell bifunctional catalysts for one-step synthesis of dimethyl ether from $\mathrm{CO}_{2}+\mathrm{H}_{2}$. Acta Phys Chim Sin 28(8), 1957-1963.

ZAERA, F. (2013). Nanostructured materials for applications in heterogeneous catalysis. Chem Soc Rev 42(7), 2746-2762.

Zhong, C.-J. \& MAYe, M.M. (2001). Core-shell assembled nanoparticles as catalysts. Adv Mater 13(19), 1507-1511. 